\title{
EPISTEMOLOGIA DE NANCY CARTWRIGHT: UMA CONTRIBUIÇÃO AO DEBATE SOBRE A NATUREZA DA CIÊNCIA ATUAL
}

\begin{abstract}
RESUMO: Este trabalho busca trazer para o debate algumas ideias propostas por NancyCartwright sobre a natureza da ciência atual. Queremos crer que sua formação centrada na matemática desafianos a lançar um olhar inovador sobre a ciência, especialmente sobre a natureza das mais profundas e bem-sucedidas leis fundamentais da Física, reinterpretando conceitos como causalidade, objetividade e realismo. As ideias aqui resumidas não abordam a complexidade de sua epistemologia, mas visam, tão somente, manter em curso o debate epistemológico e instigar novas reflexões, especialmente aos professores de física, sugerindo que a filosofia da ciência, assim como a ciência que não tem perguntas finais, mantém sua marcha e continua evoluindo.
\end{abstract}

Palavras-chave: Filosofia da ciência. Nancy Cartwright. Entidades teóricas.

\section{NANCY CARTWRIGHT'S EPISTEMOLOGY: A CONTRIBUTION TO THE DEBATE ON THE NATURE OF CURRENT SCIENCE}

ABSTRACT: This paper brings into discussion some of Nancy Cartwright's ideas about the nature of current science. We believe that her formation focused on Mathematics challenges us to an innovative look at science, especially about the nature of the deepest and the most successful fundamental laws of Physics by reinterpreting concepts as causality, objectivity and realism. The ideas summarized on this paper don't deal with the complexity of her epistemology. The aim is only to keep the course of the epistemological debate and instigate new thoughts, mostly to physics teachers. This is done by suggesting that the philosophy of science, as well as science itself, which does not have final questions, but instead keeps in march and continues its evolution.

Keywords: Philosophy of science. Nancy Cartwright. Theoretical entities.

\author{
Neusa Teresinha Massoni * \\ Marco Antonio Moreira **
}

* Doutora em Ciências pela Universidade Federal do Rio Grande do Sul (UFRGS). Professor adjunto na Universidade Federal do Rio Grande do Sul (UFRGS). Docente permanente do Programa de Pós-Graduação em Ensino de Física do Instituto de Física da Universidade Federal do Rio Grande do Sul (IFUFRGS)

E-mail: neusa.massoni@ufrgs.br

** Professor titular, aposentado, Instituto de Física da UFRGS.

E-mail: moreira@if.ufrgs.br

DOI - http://dx.doi.org/10.1590/1983-21172014160305 


\section{INTRODUÇÃO}

Apresentamos neste trabalho uma introdução às ideias de Nancy Cartwright sobre a natureza da ciência visando contribuir com o debate atual, especialmente sobre o papel das teorias, o processo de produção e as práticas da moderna Física. Cartwright é filósofa da ciência, graduada em Matemática pela Universidade de Pittsburgh, doutorou-se em Filosofia na Universidade de Illinois, Chicago. Ela tem lecionado Filosofia no Departamento de Lógica, Filosofia e Método Científico da Escola de Economia de Londres e Ciência Política na Universidade da Califórnia, San Diego. Iniciou seus trabalhos em Filosofia da Ciência na Universidade de Stanford, onde foi professora por 18 anos. Sua postura epistemológica centra-se na ciência como ela é praticada, focaliza o realismo, a causalidade, as evidências e a objetividade das teorias científicas. Trata-se de uma tentativa de abordar ideias e tendências do "fazer científico" do nosso tempo, na perspectiva dessa filósofa da ciência, mas assumindo que algumas dessas ideias nem sempre são amplamente compartilhadas.

\section{Leis Fenomenológicas versus Leis Teóricas}

$\mathrm{Na}$ introdução de seu livro intitulado How the Laws of Physics Lie (1983), um título possivelmente pouco apreciado por alguns, Cartwright aborda um antigo debate entre leis fenomenológicas e leis teóricas e afirma que filósofos da ciência e físicos diferenciam esses dois tipos de leis, mas o fazem de forma distinta. Para os filósofos da ciência, as leis fenomenológicas são sobre coisas que, pelo menos em princípio, podem ser observadas diretamente, enquanto as leis teóricas podem ser conhecidas apenas por inferência indireta. Assim, para os filósofos, os termos fenomenológico e teórico distinguem o observável do inobservável. Para os físicos, esses termos contrastam o fenomenológico e o fundamental: uma lei fenomenológica relata o que acontece postulando certas equações sem investigar profundamente seu significado, descreve algum fenômeno ou efeito que um tratamento teórico mais aprofundado pode explicar através de uma lei fundamental ${ }^{1}$. Ou seja, para estes, fenomenológico e teórico distinguem leis que são descritivas daquelas explicativas.

Para Cartwright, o debate fenomenológico versus teórico distingue realistas e antirrealistas, mas adverte que ela assume uma postura favorável a um tipo de antirrealismo ${ }^{2}$ que rejeita o teórico e aceita o fenomenológico. Contudo, destaca que isso nada tem a ver com o confronto teoria versus observação. Em vez disso, coloca o teórico em oposição ao fenomenológico, pois na moderna Física as leis fenomenológicas, que têm o papel de descrever, têm alcançado um considerável sucesso ao passo que, paradoxalmente, o poder explicativo [das leis fundamentais ou teóricas] está justamente na adequação descritiva daquelas (CARTWRIGHT, 1983, p. 3).

Em Física, argui ela, temos uma grande quantidade de leis fenomenológicas altamente confirmadas que fazem um detalhamento especializado visando testar afirmações sobre o que acontece em casos concretos; e, quando olhamos para as implicações reais das leis fundamentais, vemos que elas fazem confirmações 
apenas indiretas. Nesse sentido, seus relatos são geralmente não verdadeiros, argui, pois, se leis fenomenológicas são sobre as aparências, as fundamentais são sobre a realidade por trás das aparências. Para os realistas, adverte, se as leis fundamentais são falsas e inexatas, as fenomenológicas são ainda mais. Mas Cartwright defende o contrário: quando se trata de fazer o teste, as leis fundamentais estão mais longe daquilo que supõem explicar do que as leis fenomenológicas.

Cartwright fundamenta essa afirmação paradoxal através de três argumentos distintos e inter-relacionados e que serão, tentativamente, apreciados ao longo deste texto:

1. o poder explicativo das leis fundamentais não argumenta em favor de sua verdade;

2. a forma como as leis fundamentais são usadas para prover explicações argumenta em favor de sua "falsidade", pois explicamos por composição de causas, por aproximações que visam melhorar suas afirmações e por idealizações. Em todos esses casos não se conhecem os fatos diretamente;

3. a aparente verdade expressa pelas leis fundamentais resulta de um modelo inadequado de explicação ainda muito presente, segundo o qual se crê que é possível retirar as leis diretamente da realidade.

Ela propõe que a rota da lei teórica (ou explicativa) para a realidade dá-se da lei para o modelo e, então, do modelo para as leis fenomenológicas, que descrevem fenômenos ou objetos reais. Isso implica que as leis fundamentais da Física não são sobre objetos do mundo real, mas apenas sobre objetos em modelos, e que os testes dessas leis somente são possíveis por construção de análogos especificados por leis fenomenológicas. O realismo está nos modelos e nas leis fenomenológicas.

Assim, explicar em ciências significa construir um modelo através do qual um fenômeno se encaixa na estrutura geral de uma lei fundamental e, depois, obter análogos para suas leis fenomenológicas para fazer o teste. As leis fundamentais da Física não descrevem, de fato, regularidades do mundo real. Se insistirmos que evidências sejam um quesito relevante para sua avaliação, então, teremos que considerá-las não verdadeiras. Essa afirmação forte se deve, adverte, à tensão entre explicações causais e teóricas.

A "falsidade" das leis fundamentais, assevera, é uma consequência de seu grande poder explicativo e isso contradiz um argumento muito conhecido e bastante utilizado, segundo o qual, se uma hipótese explica uma quantidade suficientemente grande de fenômenos bastante bem, podemos inferir que a hipótese é verdadeira (CARTWRIGHT, 1983, p.4). Defensores desse argumento poderão discordar sobre o que conta como "bastante bem" ou sobre a quantidade e variedade de fenômenos explicados, argui, mas concordarão que o poder explicativo, longe de ser alheio à verdade, nos conduz a ela.

A postura de Cartwright é contrária à ideia de que uma explicação é um guia para a verdade. O que o poder explicativo tem a ver com a verdade é que há uma tendência de garantir que, se " $x$ " explica " $y$ " e " $y$ " é verdadeiro, então " $x$ " também deve 
ser verdadeiro. Mas isso é muito mais um desafio do que um argumento e somente se tem uma resposta positiva, adverte, no caso de explicações causais.

Uma explicação causal tem a importante tarefa de mostrar como várias causas se combinam para produzir um fenômeno em estudo. Supondo que desejamos descrever um processo causal concreto pelo qual um fenômeno é provocado, isso somente procede se o processo de fato ocorre e, para se ter uma explicação aceitável, temos que acreditar nas suas causas. Para exemplificar essa ideia, Cartwright relata as tentativas de explicação do radiômetro de William Crookes, inventado em 1835. O radiômetro é um pequeno moinho de vento cujas pás são pintadas de preto em um lado e de branco no outro e é encapsulado em um recipiente de vidro evacuado. Quando se faz incidir luz sobre o radiômetro, as pás rotam. A primeira explicação para o fenômeno foi a de que a pressão da luz causava a rotação, mas logo se supôs que a pressão da luz não era suficiente para gerar o movimento. Então, propôs-se que o movimento das pás devia-se à ação das moléculas de gás contidas no recipiente. Mas Crookes procurou evacuar o recipiente, e, se aceitarmos essa explicação, teremos que aceitar o fato de que o vácuo era imperfeito, já que ela supõe a presença de moléculas no recipiente. Houve duas hipóteses rivais sobre o que as moléculas de gás poderiam fazer, hoje defendidas por diferentes campos. A primeira propunha que as pás eram colocadas em movimento pela pressão das moléculas quicando mais energeticamente no lado preto. Em 1879, Maxwell, através da teoria cinética dos gases, propôs que as forças no interior de um gás são as mesmas em todas as direções e que não poderiam ser responsáveis pelo movimento das pás. Em vez disso, sugeriu que o aquecimento diferencial do gás (aquecimento maior no lado preto) produz uma tensão tangencial nas bordas provocando o deslizamento do gás, que, em média, flui do lado branco para o preto, sendo que a diferença de pressão coloca as pás em movimento com o lado branco para frente. Os opositores de Maxwell argumentam que a tensão tangencial poderia ser negligenciada.

Mas se aceitamos essa explicação temos que admitir que as moléculas do radiômetro de Crookes são invisíveis e que tensões tangenciais são o tipo de coisa que não se espera ver em primeiro plano, e, então, o que temos é uma entidade teórica (um modelo). Acredito em ambas, afirma Cartwright. Acredito nelas porque aceito a explicação causal de Maxwell de por que as pás se movem (CARTWRIGHT, 1983, p. 5). Ao produzir essa afirmação, Maxwell expôs uma lei fundamental, tal como a equação de Boltzmann ou a equação da continuidade, nas quais não acredito (CARTWRIGHT, 1983). Mas, argui, o fato é que podemos rejeitar leis teóricas sem rejeitar as entidades teóricas e isso se deve a que os modelos, às vezes, são mais robustos que as teorias. No caso das moléculas presentes no radiômetro de Crookes e da tensão tangencial de Maxwell, temos uma afirmação causal satisfatória e por isso temos boas razões para acreditar nas entidades e nos processos em questão. Assim, argui, argumentos causais são boas razões para acreditarmos em entidades teóricas.

Dado nosso conhecimento geral sobre que tipo de fatos e condições são possíveis em dadas circunstâncias, temos motivos para dispensar a estrutura 
detalhada dos efeitos e aceitar que causas características nos levam a eles. Resumo minha visão sobre explicações da seguinte forma: - a melhor explicação não é por inferência ${ }^{3}$; - inferência para as causas mais prováveis é aceitável (CARTWRIGHT, 1983, p. 6). Fazemos nossas melhores inferências causais em situações muito especiais: 1) quando nossa visão geral do mundo nos faz insistir que um fenômeno conhecido tem uma dada causa; 2) quando a causa citada é o tipo de coisa que pode nos levar ao efeito; 3) quando existe um processo apropriado conectando causa e efeito e a probabilidade de outra causa pode ser descartada. Isso mostra por que experimentos controlados são tão importantes para a "descoberta" de entidades e processos que não podemos observar, pelo menos não diretamente.

A disputa entre tensão normal e tangencial no radiômetro de Crookes ilustra um importante ponto sobre a observação e experimentação. Os instrumentalistas, que desejam acreditar somente no que podem ver, têm conseguido manter de pé um debate em que questionam: realmente "vemos" através do microscópio? Podemos ver uma interferência de fase? Mesmo a olho nu, não vemos, em qualquer caso, apenas efeitos? O fato é que muitas coisas que são realidades para os físicos são o tipo de coisas que não podem ser vistas diretamente. São aspectos não visuais como o spin do elétron, a tensão do gás na superfície das pás, a rigidez da vara etc. A observação a olho nu, nesses casos, não serve como teste de existência. Experimento sim. Experimentos são feitos para isolar causas verdadeiras de falsos pontos de partida. Assim, explicar, em Física, envolve dois tipos distintos de atividades, segundo Cartwright: primeiro, quando explicamos um fenômeno, identificamos suas causas, tentamos fornecer informações detalhadas de como exatamente o fenômeno foi produzido; segundo, adequamos o fenômeno a um sistema teórico amplo, que abarca, sob um conjunto de equações fundamentais, um grande conjunto de diferentes tipos de fenômenos.

Esse tipo de explicação é o que os filósofos da ciência chamam de leis da natureza. Mas, voltando ao exemplo do radiômetro, as leis para os dois tipos de explicação não são parecidas. Entra aí o papel das leis fenomenológicas. A história causal usa leis fenomenológicas altamente específicas, que dizem o que ocorre em situações específicas ao passo que leis fundamentais são formulações abstratas e não descrevem circunstâncias particulares.

Portanto, a função das leis é distinta. E não se trata apenas de uma diferença filosófica. São diferenças encontradas em distintas práticas científicas. Em Física, é usual que um mesmo fenômeno tenha tratamentos teóricos alternativos. Constroem-se diferentes modelos para diferentes propósitos e com diferentes equações. E se quisermos nos perguntar qual é o modelo correto? Qual é a "verdade" de certo conjunto de equações? Teremos que concluir que a pergunta é um equívoco. Distintos modelos destacam diferentes aspectos de um mesmo fenômeno e servem a diferentes propósitos. Muitas vezes, um dado modelo possibilita desvendar uma situação real em que as principais características fenomenológicas são precisamente aquelas mencionadas no modelo. Hélio a baixa densidade é quase um gás ideal do ponto de vista do modelo de bolas de bilhar da Mecânica 
Estatística. Nesses casos, somos inclinados a pensar o modelo como uma réplica da realidade e atribuir aos objetos modelados não somente as propriedades do modelo, mas também as propriedades da conveniência.

Cartwright defende que as proposições para que uma explicação causal seja aceita são princípios causais altamente detalhados e leis fenomenológicas concretas e específicas para a situação que temos à mão, e não as equações abstratas de uma teoria fundamental. O fato de que as hipóteses causais são parte de uma teoria fundamental satisfatória não é suficiente, uma vez. que seu sucesso em organizar, prever e classificar nunca é um argumento para a verdade. Aqui, como já ressaltei, a ideia do teste experimental é crucial (CARTWRIGHT, 1983, p. 98). Maxwell ao dizer que as pás são arrastadas e postas a girar pelo deslizamento do gás nas bordas obteve aceitabilidade devido a seu relato sobre o que acontece no radiômetro. Temos aqui uma lei fenomenológica - nesse caso, um princípio causal - que Maxwell utilizou: a velocidade com que as moléculas do gás deslizam sobre a superfície das pás e a correspondente tensão tangencial são afetadas pela temperatura desigual da superfície do sólido (em média, as moléculas movem-se do lado frio (branco) para o lado quente e a diferença de pressão causa o movimento das pás com o lado branco para frente).

Leis causais, argumenta ela, fazem uso de princípios causais, são objetivas, informam sobre o que faz as coisas acontecerem. Contudo, adverte, são necessárias leis teóricas para especificar exatamente com o que cada causa contribui. Ocorre que as leis teóricas não poderiam fazer isso se fossem literalmente verdadeiras, elas têm de ignorar a ação de outros fatores que poderiam ser responsáveis pelo fenômeno, isto é, necessitam de uma cláusula ceteris paribus. Voltaremos a essas noções mais adiante neste texto.

\section{LEIS DE ASSOCIAÇÃO, LEIS CAUSAIS, LEIS PROBABILÍSTICAS E ESTRATÉGIAS EFICAZES}

Segundo Cartwright, há dois tipos de leis que tentam dar conta da natureza: leis de associação e leis causais. Leis de associação são aquelas que dizem como certas qualidades ou quantidades estão associadas, e podem ser determinísticas ou probabilísticas como, por exemplo, as leis probabilísticas da genética mendeliana. As equações da Física são bons exemplos de leis de associação ("quando a força que atua em uma partícula de massa $m$ é $f$, a aceleração é $f / m$ ”). Mas têm causalidade neutra, segundo essa epistemóloga, não fornecem relatos sobre o que faz as coisas acontecerem, enquanto as leis causais têm a palavra "causa" embutida diretamente nela. Por exemplo: "fumar causa câncer". Os princípios causais, argui ela, não podem ser reduzidos a leis de associação, mas, ao mesmo tempo, não podem estar longe delas.

Os argumentos que respaldam as leis causais dependem de alguns fatos sobre "estratégias", ou seja, sobre o que é, ou não, uma boa estratégia. Cartwright usa um exemplo: a França na construção do canal da Panamá descobriu que pulverizar óleo nos pântanos era uma boa estratégia para conter a propagação da 
malária, em vez de enterrar a cobertura contaminada, que era uma estratégia inútil. O que os franceses "descobriram" foi verdade, independente de suas teorias, de seu desejo de controlar a malária ou dos custos gerados. É importante diferenciar estratégias eficazes e ineficazes porque a diferença entre elas depende do tipo de leis causais que utilizamos e é uma dependência em nada fraca.

Para Nancy Cartwright, uma lei causal do tipo "C causa E" não deve ser entendida como uma lei universal, pois é quantificada sobre particulares. Sempre se refere a fatos particulares. É verdade, afirma ela, que a lei causal "aspirina alivia a dor de cabeça" funciona bem, mas sempre pode haver alguma que falha em fazer isso. Assim, leis causais fazem afirmações que relacionam estratégias a verdades genéricas, e não devem ser confundidas com leis estatísticas, embora aquelas estejam relacionadas a estas. Uma causa pode aumentar a frequência de seu efeito, mas tal fato pode não mostrar em que probabilidade outras causas estão atuando. É possível que correlações entre uma suposta causa e outros fatores causais ocultem o aumento de probabilidade que deveria aparecer. Por exemplo, se se supõe que fumar causa doenças do coração, então se espera que a probabilidade de ocorrer doenças do coração seja maior entre fumantes (espera-se que $\operatorname{prob}(\mathrm{H} / \mathrm{S})>\operatorname{prob}(\mathrm{H})$ ). Essa expectativa pode ser falsa dado que, mesmo que fumar cause doenças do coração, o esperado aumento de probabilidade pode não aparecer se os fumantes estiverem correlacionados a alguma medida de prevenção suficientemente forte, como praticar exercícios físicos, por exemplo. Se praticar exercícios físicos é mais eficaz na prevenção de doenças do coração do que fumar o é em causá-las, então em uma população em que fumantes e praticantes de exercícios estão altamente correlacionados pode ser verdade que $\operatorname{prob}(\mathrm{H} / \mathrm{S})=\operatorname{prob}(\mathrm{H})$ ou mesmo que prob(H/S) < prob(H), já que entre os fumantes também há praticantes de exercícios físicos. Dessa forma, quando uma causa falha em aumentar a probabilidade dos efeitos, significa que ela pode estar correlacionada a outros fatores causais que dominam seus efeitos. Assim, uma causa pode aumentar a probabilidade de seus efeitos, mas somente em situações em que essas correlações estão ausentes.

O que explica o quê depende de leis e de fatos reais do nosso mundo que podem não estar suficientemente ajustados, segundo Cartwright. Outro exemplo: se dois pedaços de material radioativo (urânio 238 e plutônio 214) são colocados aleatoriamente em frente a um contador Geiger por algum tempo, temos que considerar que a vida média do plutônio é curta e a probabilidade de clicks [no contador] é 0,9; que a vida média do urânio é longa e a probabilidade é 0,1 , tal que a probabilidade total para um grande número de clicks é 0,5 , segundo as leis estatísticas. Dessa forma, a probabilidade condicional de o contador clicar quando o urânio está presente é menor que a probabilidade incondicional (quando o urânio ausente). Nesse caso, o urânio diminui a probabilidade do seu efeito. Ocorre que o urânio gera um grande número de clicks no contador, quer o plutônio esteja ou não presente. Então, o que conta como explicação para o urânio gerar um grande número de clicks no contador Geiger não é uma 
lei probabilística do tipo [Prob(clicks/urânio) < Prob(clicks)], mas, em vez disso, é uma lei causal do tipo "urânio causa radioatividade". Isso mostra diferenças importantes entre leis causais e leis probabilísticas.

Como já dito, nem sempre as causas aumentam a probabilidade de seus efeitos, especialmente se a causa está correlacionada com algum outro fator causal que domina os efeitos, ou seja, é possível mostrar que uma causa não necessariamente aumenta a probabilidade de seu efeito. Embora Cartwright não tenha a pretensão de oferecer um modelo de explicação causal, afirma que certas teses negativas resultam de sua visão, por exemplo: estar sob uma lei causal não é suficiente nem necessário para explicar um fenômeno. Aliás, não é suficiente nem necessário para oferecer qualquer explicação. Isso resulta do fato de que as leis causais não são transitivas, isto é, um fenômeno pode ser explicado por um fator que pode estar associado a uma sequência de passos intervenientes, e cada passo pode estar sob alguma lei causal de forma que não é possível especificar uma lei causal única que vincule a explicação ao fenômeno em si a ser explicado.

A quantidade $\operatorname{Prob}(\mathrm{E} / \mathrm{C}, \mathrm{Kj})$ que aparece em uma condição causal e que é importante para avaliar a eficácia das estratégias é chamada pelos estatísticos de probabilidade condicional parcial de E em C, mantendo Kj fixo. O que é especialmente significativo sobre a probabilidade condicional parcial, afirma ela, é o fato de que isso requer que sejam fixados todos, e somente eles, os fatores causais. A escolha da partição $\{\mathrm{K} j\}$ é um aspecto crítico para medir a eficácia das estratégias, mas também é essencial considerar diferentes partições para um mesmo espaço para saber se uma estratégia é efetiva ou não. A partição correta é determinada pelo que as leis causais são, e, se não se admitem leis causais, não existe procedimento para distinguir fatores adequados. A objetividade das estratégias requer a objetividade das leis causais. Tenho defendido que devemos estar comprometidos com a existência da causa, se quisermos aceitar uma determinada explicação causal (CARTWRIGHT, 1983, p. 97).

\section{A INVERDADE DAS LEIS}

É compartilhado que teorias científicas são propostas para explicar pela descrição que fazem da realidade e que, cumprida tal tarefa, o processo pode acabar, já que descrever a natureza (explicitar leis, definir valores de constantes fundamentais, estimar a distribuição de massa etc.) é fazer um depoimento de como fazemos para explicar.

Isso é um equivoco, afirma Cartwright (CARTWRIGHT, 1983, p. 94). É fomentado por um modelo de explicação também equivocado, segundo o qual tudo o que precisamos saber são as leis da natureza, um pouco de lógica, talvez um pouco de teoria probabilística e então podemos especificar quais fatores podem explicar quais outros. Mas generalizações muito amplas (leis de cobertura) não podem ir longe, segundo Cartwright. Se nos perguntarmos: qual o papel do DNA na herança genética? O que forma o arco-íris quando a luz do sol é refratada pelas gotas de chuva? 
Teremos que aceitar que não podemos explicar esses fenômenos com leis de cobertura e, mais ainda, que não temos leis que os cobrem integralmente. Muitos fenômenos para os quais temos boas explicações não são cobertos por nenhuma lei.

Generalizações cobrem muitos fenômenos, mas estão presas a condições muito especiais, usualmente condições ideais, e leis que podem desempenhar muitas funções são falsas, segundo Cartwright. A inverdade das leis fundamentais está nisso.

Não existem generalizações excepcionais, segundo essa epistemóloga (CARTWRIGHT, 1983, p. 46), e, olhando para as equações da Física, é mais plausível dizer que não existem leis quantitativas excepcionais. Não só não existem como nossas melhores candidatas estão fadadas a falhar. Isso vai ao encontro da tese de Popper (1982) de que toda a teoria é passível de falseamento e de Bachelard (1973) de que o conhecimento científico é sempre a reforma de uma ilusão. Mesmo as leis precisas e detalhadas da Física apresentam alguma forma de deficiência. São sempre aproximadas.

Certas leis físicas são tratadas como se fossem excepcionais e, embora não o sejam, são mantidas nos livros de texto por decisão dos cientistas. A Lei de Snell sobre o ângulo de incidência e de refração da luz $\left(\operatorname{sen} \theta_{1} / \operatorname{sen} \theta_{2}=n_{1} / n_{2}, \operatorname{com}\right.$ $n_{1}=c / v_{1}$ e $n_{2}=c / n_{2}$, sendo $v_{1}$ e $v_{2}$ as velocidades de propagação da luz em dois meios distintos) é um desses exemplos que aparecem nos livros de texto de Óptica. Só mais tarde, afirma Cartwright, quando a Lei de Snell é derivada da teoria eletromagnética da luz, é que se aprende que a forma como ela é apresentada na Óptica, na verdade, é válida somente para meios cujas propriedades são isotrópicas ${ }^{4}$.

Caberia, então, uma pergunta: se existe um tratamento mais refinado para a Lei de Snell que a valida para algumas circunstâncias especiais, quando os meios são isotrópicos, por que permanece a forma não refinada da Lei de Snell nos livros de Óptica? Existem, segundo Cartwright, razões pedagógicas para isso. Mas existirão razões científicas? Cartwright responde afirmativamente. As razões têm a ver com a tarefa principal da ciência: a de explicar. Leis fundamentais expressam nosso compromisso explicativo.

Uma vez conhecidas as leis, temos que decidir que tipo de fator pode ser abarcado pela explicação. Sabemos da Lei de Snell refinada que, em qualquer meio isotrópico, o ângulo de refração pode ser explicado pelo ângulo de incidência segundo a equação $\operatorname{sen} \theta_{1} / \operatorname{sen} \theta_{2}=\mathrm{n}_{1} / \mathrm{n}_{2}$. Manter a versão não refinada da Lei de Snell nos livros é sinal de que o mesmo tipo de explicação pode ser dado também a meios anisotrópicos. Assim, adverte ela, é preciso admitir leis do tipo ceteris paribus ${ }^{5}$, em que o modelo de explicação derivado de situações ideais é empregado mesmo quando as condições são menos precisas. A Lei de Snell é um exemplo disso. Assume-se que podemos entender o que acontece em um meio "quase" isotrópico ensaiando como os raios de luz se comportam em um meio isotrópico puro. O que fazemos é tomar a decisão de explicar os ângulos para os raios refratados em meios anisotrópicos da mesma maneira como explicamos para meios isotrópicos e fazemos isso porque sabemos que, se o meio é "quase" isotrópico, os raios estarão 
muito próximos daqueles previstos pela Lei de Snell refinada. Tomamos essa decisão forçados não pelo nosso conhecimento das leis da natureza, mas o fazemos muito mais pela escassez de leis. Não temos uma lei para tudo o que acontece em condições abaixo das ideais.

Os críticos às leis ceteris paribus (todos os demais fatores se mantêm inalterados) sustentam que estaríamos fazendo uma aposta sobre a verdade das leis. Por exemplo, manter a forma não refinada da Lei de Snell significaria "apostar" que a lei para meios anisotrópicos assume valores muito próximos daqueles da Lei de Snell refinada. Cartwright discorda dessa crítica por dois motivos: primeiro, acredita em uma possibilidade metafísica, ou seja, considera falsa a tese de que possam existir leis capazes de cobrir todos os casos. Eu imagino que os objetos naturais são muito parecidos com pessoas na sociedade. Seu comportamento é restringido por algumas leis especificas e por um punhado de princípios gerais, mas não é determinado em detalhe... (CARTWRIGHT, 1983, p. 49); segundo, defende que a lei que temos em nossa teoria não é completa, não é uma lei que possamos confirmar ou testar de forma definitiva. As leis da natureza que conhecemos em algum momento requerem uma decisão, e é justamente essa decisão que os teóricos tomam quando acenam para a existência de "entidades teóricas" ou "modelos".

No entanto, é legítimo aceitar explicações que fazem uso de leis ceteris paribus, embora, literalmente, sejam falsas como afirmações descritivas, mas mantê-las não é algo surpreendente porque queremos leis que verifiquem e, ao mesmo tempo, o que acontece deve ser bem variado e diversificado.

\section{MODELOS E O PAPEL DAS LEIS DA FÍSICA}

Existe uma herança empirista ainda muito enraizada em que se crê que as leis da natureza descrevem fatos da realidade. Se os fatos que temos à mão são suficientemente parecidos com aqueles descritos na lei, então consideramos que a lei é verdadeira. Cartwright chama isso de factibilidade das leis.

Ocorre que as leis fundamentais da Física não descrevem fatos reais, no dizer dessa epistemóloga. Tomadas como descrições de fatos, elas são falsas e, nesse sentido, "mentem". Ela contrasta a Física com a Biologia para explicitar essa sua visão. Em Biologia, à semelhança da Engenharia, qualquer afirmação geral sobre sistemas complexos, como um organismo vivo ou um rádio, trata de sistemas específicos. As afirmações da Biologia e da Engenharia não são leis porque não apresentam exceções. Elas falam como os organismos ou sistemas reais se comportam, informam o que esses sistemas fazem algumas vezes, a maior parte do tempo ou sempre. Dizem onde um determinado tipo de peixe vive, como nada, como e de que se alimenta etc. As leis da Física, ao contrário das leis biológicas e as da Engenharia, não falam o que os objetos fazem.

Mas, se as leis fundamentais da Física não descrevem como as coisas se comportam, o que fazem então? Para Cartwright, o físico Richard Feynman (1967) 
em sua obra The Character of Physical Law oferece uma ideia, uma metáfora útil na tentativa de responder a essa questão. Ele afirma que existem ritmos, padrões entre os fenômenos da natureza que não estão aparentes aos olhos, mas apenas aos olhos da análise e esses ritmos e padrões é que chamamos de leis da Física. Feynman não afirma que as leis que a Física estuda descrevem os fatos e eu digo que as leis da Física não fornecem descrições da realidade (CARTWRIGHT, 1983, p. 55-56). É nesse sentido que a concepção epistemológica de Cartwright assume um viés antirrealista.

Visando reafirmar sua postura antirrealista, Cartwright referencia duas outras, extremadas e distintas sobre o que conta como explicação: de um lado, ideias de Bas van Fraassen ${ }^{7}$, um sofisticado instrumentalista que se preocupa com entidades inobserváveis e com as evidências que nossas explicações teóricas respaldam de como tais entidades se comportam, ou seja, ele concorda que produzir teorias empiricamente adequadas é relevante, mas argui que acreditar na verdade de explicações muito amplas não passa de uma assunção gratuita. De outro, ideias de Hilary Putnam ${ }^{8}$ e seu realismo interno, que sustenta que a verdade é um ideal regulador em direção ao qual nossa investigação racional deve convergir, mas argumenta [como nominalista transcendental, como é conhecido] que, uma vez que o pensamento pode nunca se conectar com a realidade, nosso conhecimento pode atingir, na melhor das hipóteses, certa coerência interna. O que esses filósofos têm em comum é que ambos defendem uma linha argumentativa de que leis fundamentais (explicativas) da Física não representam fatos da realidade, assevera Cartwright.

Mas Cartwright discorda dessas posturas extremadas. Argumenta que podemos permitir que qualquer tipo de declaração represente fatos da natureza, incluindo as afirmações específicas da Biologia e da Engenharia, mas que as leis explicativas fundamentais da Física não são "verdades" porque não descrevem, de fato, o mundo real, a não ser por entidades ideais (ou modelos) que podem ser tomadas realisticamente. Assim, "verdade" e "explicação" são mutuamente excludentes. Mais adiante (CARTWRIGHT, 1983, p. 87 e seguintes) Cartwright confronta essas ideias de Bas van Fraassen com as de Pierre Duhem ${ }^{9}$ e enfatiza que este último rejeita as leis teóricas por entender que elas só se fundamentam em sua habilidade de explicar, que não são "verdades", embora ele não se oponha às leis fenomenológicas, que podem ser confirmadas por métodos indutivos. Mas Cartwright assevera que nem Van Fraassen, nem Duhem se opõem à inferência no sentido geral. O que ambos atacam é um tipo específico de inferência - a "inferência para a melhor explicação”, que consideram ser inválida. Admitem [esses pensadores], embora não acreditem em causas, que muitas inferências são fortes e que alguns fenômenos podem ser derivados de certos princípios fundamentais.

Cartwright considera esses argumentos persuasivos e até compartilha com eles alguns aspectos, por exemplo, o antirrealismo a respeito das leis teóricas (ou fundamentais), por entender que estas não governam fatos e objetos do mundo real, mas acredito em entidades teóricas (CARTWRIGHT, 1983, p. 89). Defende ela que explicações através de entidades teóricas (modelos) podem ser tomadas como 
explicações causais e argui em favor da tese de que inferência de efeitos para causa é legítima. Assim, podemos ser realistas sobre entidades teóricas.

Quando infiro, diz a epistemóloga, do efeito para a causa, me pergunto o que faz o efeito ocorrer. Não aceito uma explicação do tipo que explica tudo, a menos que ela apresente a causa. E aceitando a explicação estou aceitando não só que ela explica, no sentido de organizar e esclarecer, mas que ela apresenta de fato uma causa. Por exemplo, se água suja se acumula na base de uma planta doente, então ela é a causa da doença. Para darmos uma explicação para a doença (efeito), torna-se absolutamente necessário apresentar a suposta causa, no caso, a água suja. E, para que a explicação possa ser tomada como verdadeira, deve existir tal água.

Uma explicação do efeito para a causa tem um componente existencial e este não é apenas um ingrediente opcional. Podemos inferir a melhor explicação, mas não de forma derivativa. Inferir para a causa mais provável é legítimo, e tal causa é um item específico que chamamos de entidade teórica. Entidades teóricas às vezes são mais robustas que as teorias. $\mathrm{O}$ elétron, claramente, não é uma entidade de uma única teoria, de uma teoria particular. Um elétron é um ente sobre o qual temos várias teorias, algumas incompletas e conflituosas (a de Bohr, a de Rutherford, a de Lorentz). Cartwright defende que inferências para a causa mais provável têm uma força lógica maior que a inferência para a melhor explicação. Para dada situação específica, as leis fundamentais são supostas como se fizessem as mesmas afirmações que as mais concretas leis fenomenológicas que elas explicam. Isso resulta do fato de que leis fenomenológicas podem ser deduzidas das leis fundamentais. Aqui aparece um elo entre as leis fundamentais e as leis fenomenológicas.

Cartwrightdestacaquesuavisãoalinha-seàdeIan Hacking ${ }^{10}$, queafirmaqueum expertacredita em elétrons porque os usa para "criar" novos fenômenos e que, quando podemos manipularnossas entidades teóricas (modelos) bastante bem e de maneira detalhada para intervir em outros processos, então temos a melhor evidência possível para afirmar sobre o que essas entidades podem ou não fazer. Entidades teóricas bem-justificadas, por afirmações causais bem-testadas, raramente foram descartadas na historia da ciência, são robustas e podem sobreviver às teorias.

Acredito em entidades teóricas, afirma Cartwright, mas não acredito em leis teóricas. Em geral, quando tento explicar minha visão sobre leis teóricas, tenho enfrentado um padrão realista do tipo: "como pode uma lei explicar se não é verdadeira? Van Fraassen e Duhem replicariam isso perguntando "o que na explicação garante a verdade?. Penso que não existe uma resposta plausivel para essa questão quando uma lei explica outra. Mas quando argumentamos sobre entidades teóricas a situação é diferente. A argumentação é causal. Aceitar a explicação é admitir a causa (CARTWRIGHT, 1983, p. 99). 


\section{EXPLICAÇÕES POR COMPOSIC̣ÃO DE CAUSAS}

Argui Cartwright que uma teoria física fornece um esquema explicativo em que fenômenos de interesse podem ser enquadrados e que os simplifica e organiza tal que se pode tratar de forma similar acontecimentos que são fenomenologicamente distintos e, diferentemente, alguns que são fenomenologicamente idênticos.

A Dinâmica, através da lei de adição de vetores ${ }^{11}$, é um caso especial. Isso não significa dizer que não existe verdade quando esses tipos específicos de causas se combinam, mas, em vez disso, que as teorias podem ter procedimentos específicos de um caso para outro. Além da composição de causas existem outros métodos de explicação que podemos empregar, alguns são compatíveis com a facticidade das leis. Explicações através de leis de cobertura constituem um primeiro exemplo. No caso da Lei de Coulomb ou da Lei da Gravitação, sabemos como escrever uma lei mais complexa, através da adição vetorial, capaz de dizer o que acontece quando um sistema tem ao mesmo tempo massa e carga. Mas, afirma Cartwright, esses casos são muito raros. Tenho defendido que devemos estar comprometidos com a existência da causa, se quisermos aceitar uma determinada explicação causal (CARTWRIGHT, 1983, p. 97).

Se afirmarmos que leis fundamentais são sobre o que acontece quando somente uma causa simples está atuando, então, afirma Cartwright, podemos supor que a lei fornece uma descrição verdadeira. Mas o problema surge quando tentamos tomar a lei para explicar um grande número de coisas que acontecem quando muitas causas estão atuando. Esse é o ponto. Não há dificuldade em escrevermos leis supostamente mais verdadeiras, do tipo se não existem cargas, então a força entre duas massas m e m' separadas por uma distância ré Gmm'/ $r^{2}$. Podemos considerar que essa lei é verdadeira ou pelo menos que descreve o que acontece com boa aproximação. O problema é que isoladamente ela não ajuda muito quando outras forças - e.g. elétrica ou magnética - também estão agindo.

Leis da Física que alcançam um elevado grau de "verdade" (realidade) não explicam muito. Poderíamos conhecer toda a verdade das leis da natureza e ainda assim não saberíamos explicar casos compostos, argumenta Cartwright. Não existem dois meios para dar uma explicação: uma lei para ocasiões raras quando as causas ocorrem separadamente, e outra secreta, inominada, para quando as causas ocorrem em combinação. Explicações devem funcionar igualmente, tanto se apenas uma causa está agindo, quanto para composições de causas. A lição a ser aprendida é que as leis científicas que explicam por composição de causas falham em satisfazer o requisito da factibilidade. Se as leis da Física têm o papel de explicar como os fenômenos ocorrem, elas não podem afirmar os fatos (CARTWRIGHT, 1983, p. 73). Pelo menos não ao pé da letra, mesmo porque o excesso de realismo deteria seu poder explicativo. 


\section{O PAPEL DAS LEIS FENOMENOLÓGICAS}

Leis fenomenológicas e leis fundamentais se relacionam na medida em que o poder explicativo destas não está na existência de um grande número de leis [fundamentais] para determinar quais leis fenomenológicas são válidas, mas sim o contrário. Temos um grande número de leis fenomenológicas em todas as áreas da Física Aplicada e da Engenharia que fornecem descrições altamente precisas e detalhadas do que acontece em situações realistas. Em um tratamento explicativo, as leis fenomenológicas não são derivadas diretamente de leis fundamentais a não ser por uma longa série de aproximações (CARTWRIGHT, 1983, p. 121). Ela concorda que as leis básicas e as equações das nossas teorias fundamentais organizam e classificam nosso conhecimento de uma maneira eficiente e elegante e que nos permitem fazer cálculos precisos e predições. Concorda que o enorme poder explicativo e preditivo de nossas teorias está em suas leis fundamentais, mas assevera que o "conteúdo" do nosso conhecimento se expressa em leis fenomenológicas.

Assevera, contudo, que não faz sentido pensar que uma lei deriva de outra, que as leis fundamentais são básicas e que as outras (leis fenomenológicas) se mantêm por causa das leis fundamentais; nem o modelo nomológico-dedutivo ${ }^{12}$ de explicação científica se sustenta na atual prática explicativa, pois não se observam relações dedutivas entre as leis de uma explicação científica buscando formalizar relações causais.

Não há uma dedução estrita capaz de levar de uma lei fundamental, no início, para uma lei fenomenológica, no final. Em vez disso, é preciso fazer uma grande variedade de aproximações e correções. Em qualquer campo da Física existe no máximo um punhado de soluções rigorosas, e estas usualmente são para situações altamente artificiais. Na Engenharia, esse aspecto fica ainda mais acentuado. Supomos que soluções rigorosas oferecem resultados melhores, mas, por causa das dificuldades de cálculo, nos contentamos com algumas aproximações. Isso significa que, dependendo do nível das aproximações, afastamo-nos da teoria pouco a pouco. Aqui Cartwright faz uso de um exemplo: supondo que desejemos construir um amplificador como o representado na figura 1.1; existem pelo menos duas formas de calcular as propriedades do sinal: o modelo-T da figura 1.2, e o modelo $\pi$-hibrido, da figura 1.3. O primeiro, argui ela, substitui o modelo de um circuito pelo transistor e analisa a retransmissão resultante; o segundo caracteriza o transistor como um conjunto de duas portas e calcula as propriedades do sinal amplificado em termos desses parâmetros. A aplicação desses modelos de transistores oferece uma primeira aproximação dos parâmetros de transistores em baixa frequência que fazem uso das equações previstas na teoria, ou seja, os parâmetros podem ser teoricamente estimados sem ter que fazer qualquer medida em situação real, embora tais estimativas possam ser imprecisas devido às características específicas dos circuitos, que foram omitidas nos modelos. Existem, certamente, muitas maneiras distintas de tratar esse problema, mas todas recairão na construção de 
modelos mais complexos e específicos. Nesse sentido, os modelos de circuitos (figuras 1.2 e 1.3) são idealizações; mas idealizações que não parecem contrariar o realismo, pois os fatores omitidos não são muito importantes ou, em princípio, sabe-se como tratá-los.

A ideia, segundo Cartwright, é bem esta. Usar um modelo é simplificar o que ocorre na realidade. Mas um tipo de simplificação que omite algumas características menos relevantes, como, por exemplo, a resistência no capacitor bypass, sendo que em muitos casos os fatores omitidos fariam uma contribuição insignificante no fenômeno ou efeito em estudo. Omissões assim não são essenciais para as idealizações, especialmente aquelas que são de fato usadas por engenheiros no estudo de situações reais.

Figuras 1.1, 1.2 e 1.3: distintos modelos esquemáticos de um amplificador (extraído de CARTWRIGHT, 1983, p. 108).
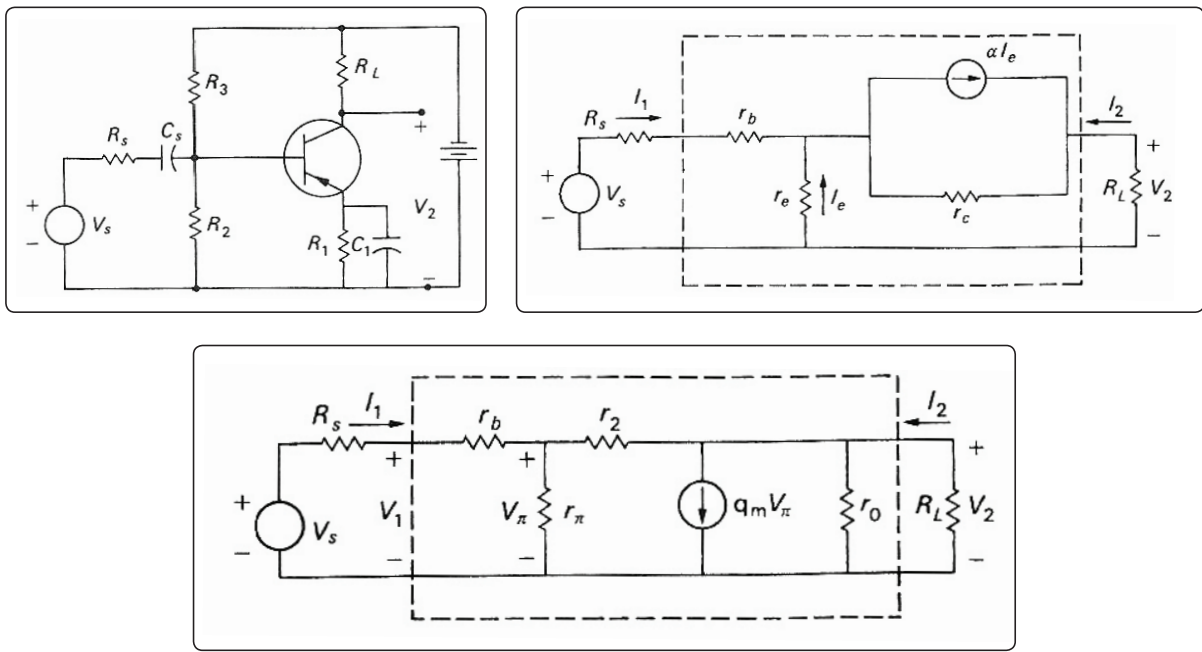

Em geral, para tornar os cálculos possíveis, começa-se com uma equação que é inadequada, mas que se sabe que pode ser melhorada e, então, acrescenta-se um fator de correção fenomenológico que ajuda a produzir uma descrição mais adequada, porém um fator não ditado pela lei fundamental. Usualmente não temos, argui Cartwright, procedimentos uniformes para "adicionar" interações. Quando tentamos escrever a equação "mais correta" puxamos uma longa lista de leis complicadas de diferentes formas, e não um punhado de equações simples (...) (CARTWRIGHT, 1983, p. 112).

Por esses procedimentos aprende-se que temos um grande número de leis fenomenológicas em todas as áreas da Física Aplicada e Engenharia que fornecem descrições detalhadas do que acontece em situações reais; em um tratamento explicativo essas somente são derivadas de leis fundamentais por uma longa série de aproximações e correções. Quase sempre essas correções melhoram o afirmado nas leis fundamentais, e, mesmo quando estas são mantidas em sua forma original, os passos da derivação não são frequentemente ditados pelos fatos. Isso cria sérios 
problemas ao modelo nomológico-dedutivo e à concepção de que leis fundamentais são melhores. Quando se trata de descrever o mundo real, as leis fenomenológicas vencem (CARTWRIGHT, 1983, p. 127).

Pode ser útil, nesse momento, fazer um paralelo entre a posição epistemológica de Cartwright e a do filósofo da ciência Mario Bunge. Ambos concordam fortemente com o papel fundamental que os modelos assumem na construção do conhecimento científico. Parecem, contudo, ter posturas distintas com relação às leis fenomenológicas.

Para Bunge, o "método" da ciência começa com objetos-modelo. É possível modelar qualquer organismo, objeto ou fato construindo-se objetos-modelo, que são representações esquemáticas ou simplificações da realidade; o passo seguinte é enriquecer essas imagens conceituais, atribuindo-lhes certas propriedades, na maioria das vezes, não observáveis, e expandindo-as em modelos teóricos progressivamente mais complexos e mais fiéis aos fatos. Os modelos teóricos fazem afirmações conceituais logicamente consistentes e são, então, enxertados em teorias mais gerais, sendo que só o que se pode submeter a provas empíricas são os modelos teóricos. As teorias gerais permanecem incomprováveis, a menos que sejam enriquecidas com modelos de seus referentes. Os referentes são, esses sim, classes de objetos concretos (BUNGE, 1974, p. 30-32). Teorias de caixa preta são, para ela, aquelas cujas variáveis são todas externas, como mostradores que representam propriedades observáveis e mensuráveis (por exemplo, a magnitude e direção do movimento dos corpos em Cinemática, sem preocupações com as causas, que pertencem à Dinâmica). Para colocar a caixa em funcionamento, precisa-se apenas manipular os mostradores como se fossem unidades destituídas de estrutura interna, isto é, oferecem-se explicações olhando de relance para os fenômenos.

Teorias de caixa-preta, afirma Bunge, são também chamadas fenomenológicas (1974, p. 69) e têm a debilidade de oferecer explicações apenas superficiais, embora sejam inevitáveis nos primeiros estágios da teorização, quando se negligenciam os detalhes e se levam em conta somente os efeitos globais. O que deve ser feito é submetê-las a teorias representacionais (teorias de caixa translúcida) que explicitam os mecanismos internos.

O caminho explicativo começa, para Bunge, com simplificações (objetos-modelo), depois se abandona a teoria de caixa-preta passando para a teoria de caixa translúcida (modelo teórico). Um exemplo do esquema proposto por Bunge pode ser o fenômeno soluto em solução diluida; o objeto-modelo é o do gás perfeito; o modelo teórico é a teoria cinética dos gases; e a teoria mais geral é a Termodinâmica.

Cartwright, por sua vez, entende que a rota da ciência é da teoria para a realidade. Parte-se de alguma teoria fundamental (não factual, pois mesmo as melhores teorias da Física não descrevem fatos verdadeiros) e constrói-se um modelo, um esquema explicativo tentativo e salta-se para as leis fenomenológicas que descrevem realisticamente os fatos. Toda teoria fundamental é "não verdadeira" e só faz sentido porque suportada por um conjunto grande de leis fenomenológicas, que descrevem detalhadamente o que acontece no mundo. Leis 
fenomenológicas somente são derivadas de leis fundamentais por uma série de aproximações. Assim, o elo entre a teoria e a realidade são os modelos. Cada modelo tem suas vantagens e desvantagens. Para diferentes propósitos, usamos diferentes modelos, com leis diferentes e até incompatíveis e não existe um modelo único que se ajusta exatamente a todas as circunstâncias. Os modelos, para ela, são robustos e podem sobreviver às teorias, que são falíveis, enquanto, para Bunge, os modelos só ganham sentido quando inseridos em alguma lei geral.

Construiu-se, tentativamente, um esquema para essas duas visões, mostrado na Figura 2: para Cartwright, o "conteúdo" de nosso conhecimento está expresso nas leis fenomenológicas que descrevem a realidade e se relacionam com as leis fundamentais não de forma dedutiva, mas por aproximações e correções, sendo que a realidade somente pode ser explicada por teorias fundamentais (explicativas) que fazem uso de "modelos" ou "entidades teóricas", ou seja, as leis fundamentais não são sobre objetos reais, mas sobre objetos em "modelos".

Para Bunge, as teorias fenomenológicas são o que ele chama de "teorias de caixa-preta” (BUNGE, 1974, p.69), pois oferecem apenas explicações superficiais, ou seja, parte-se de "objetos-modelo" (simplificações) para depois enriquecê-los tornando-os "modelos teóricos" ou teorias específicas e, depois, enxerta estes em teorias gerais. Assim um "modelo teórico" sempre tem um referente real, uma classe de objetos concretos.

Figura 2: Esquemas sobre o caminho explicativo e o papel dos modelos segundo as visões de Cartwright e de Bunge.

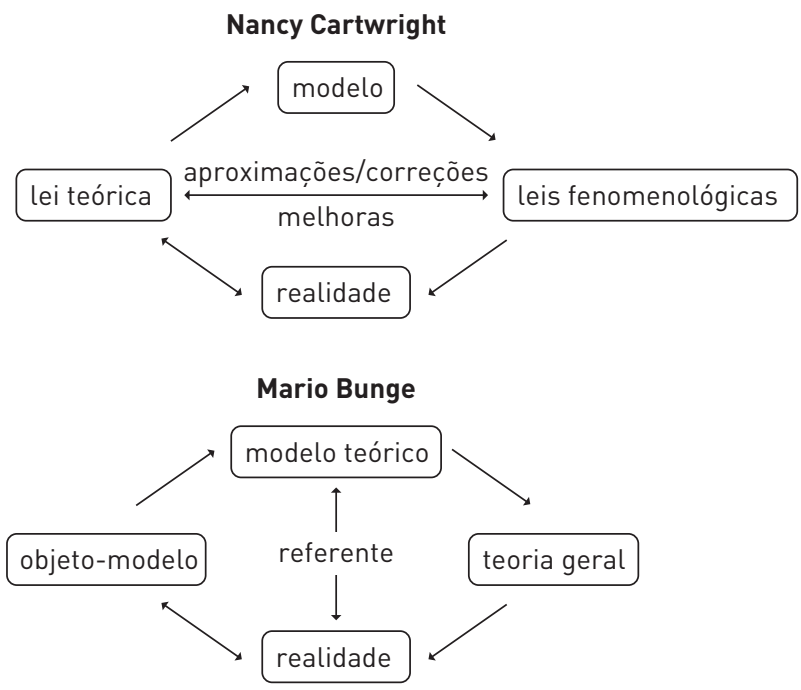

Bunge parece defender uma postura divergente daquela de Cartwright com relação ao papel das leis fenomenológicas ao afirmar que o que atrapalha o progresso do conhecimento não é a multiplicação das teorias de caixa-preta, mas a filosofia que enaltece a teoria fenomenológica como o mais alto tipo de sistematização científica e injúria a 
teoria representacional. (...) teorias não fenomenológicas e a epistemologia realista que estimula a sua construção devem ser, em última análise, preferidas (...) (grifo nosso, BUNGE, 1974, p. 90). Como dito, tanto Bunge quanto Cartwright concordam que os modelos desempenham um papel central na ciência, mas a perspectiva é distinta.

\section{CAUSALIDADE E OBJETIVIDADE}

Para Cartwright, o conteúdo real de nossas teorias físicas está no conhecimento causal ${ }^{13}$ detalhado que elas fornecem de processos concretos, com materiais reais. E essas relações causais somente se sustentam através de qualidades, não de quantidades. Mas materiais reais são constituídos de átomos e moléculas com massas, spins, cargas, numericamente especificados, sendo que essas entidades se comportam de determinada forma devido a suas massas, spins, cargas, e nossas análises teóricas de processos causais envolvem a produção e os cálculos precisos de outras quantidades, tais como a formação de linhas na espectroscopia, ou coeficientes de transporte na Mecânica Estatística. Por que, então, exigir que esses processos sejam essencialmente qualitativos? A resposta é que nosso conhecimento sobre eles, embora detalhado e preciso, não se expressa em equações quantitativas simples como aquelas que estudamos em Física Teórica. A questão não está na dicotomia quantitativo e qualitativo, mas reside no mundo ordenado e simples das equações matemáticas de teorias abstratas e as intrincadas descrições que expressam nosso conhecimento do que ocorre em sistemas reais, constituído de materiais reais. Em outras palavras, podemos usar as equações fundamentais da Física para calcular dados quantitativos precisos sobre situações reais, mas as leis fundamentais abstratas não são comparáveis às complicadas leis que descrevem a realidade porque, afirma Cartwright, minha visão básica é que equações fundamentais não governam objetos na realidade; elas governam somente objetos em modelos (CARTWRIGHT, 1983, p. 129).

Chalmers (1999, p. 25-26) ao criticar o empirismo-indutivismo ingênuo coloca a seguinte questão: por que meios é possivel deduzir afirmações universais (afirmações sobre propriedades ou comportamentos de algum aspecto do universo e se referem a todos os eventos de um tipo específico em todos os lugares e em todos os tempos) a partir de afirmações singulares (proposições sobre uma ocorrência específica, em um lugar específico e em um tempo específico)? Em uma linguagem mais atual, Catwright, ao defender as leis fenomenológicas como as que lidam com o real e que a verdade das leis explicativas depende da adequação daquelas, assume, de certa forma, um neoempirismo. Explicitamos: a resposta do indutivista ingênuo é que a indução legitima a conversão do singular para o universal; a resposta de Cartwright é que os modelos podem fazer essa transição.

Mesmo quando temos boas explicações, afirma ela, o operador "como $s e$ " assume um papel de destaque. Por exemplo: moléculas radiantes de ammonia maser $^{14}$ se comportam como se fossem osciladores clássicos. Não faz sentido nos perguntarmos "como estão distribuídos esses osciladores na cavidade maser?". 
E não faz sentido porque osciladores clássicos são construções teóricas, embora não se possa negar que a cavidade contém átomos. Reconhece-se a existência de fatos, mas coloca-se o operador "como se" no começo. Assim, as coisas colocadas à esquerda do operador representam nosso compromisso existencial e do lado direito, em geral em Física, o que aparece é justamente o que se precisa saber para escrever a equação que dá início ao tratamento matemático. Diz-se que "um átomo real" comporta-se como um oscilador clássico e a teoria nos fala qual equação é obedecida por um oscilador clássico. Aparecem então duas funções distintas do operador "como se", as descrições à esquerda descrevem o que existe e são escolhidas por sua adequação descritiva ao mundo, e as descrições à direita são aquelas que dão origem às equações e devem ser escolhidas por suas características matemáticas. Essas funções são distintas, pois fazer uma descrição para a qual a teoria fornece uma equação pode ser relativamente independente de expressar o compromisso existencial.

Ocorre que as teorias têm um estoque muito limitado de princípios para ir das descrições às equações, e os princípios requerem informações de um tipo muito particular, estruturadas de forma particular e as descrições que melhor descrevem não são geralmente aquelas às quais as equações se ajustam.

\section{ESTÁGIOS DA TEORIA}

Partindo do pressuposto de que proposições teóricas são de dois tipos: princípios internos (dizem como entidades e processos da teoria se comportam) e princípios ponte (associam a teoria a aspectos da realidade mais acessíveis a nós - associam descrições da teoria com alguns tipos de observações ou com um vocabulário antecipadamente conhecido), segundo Cartwright, teoria de entrada avança em dois estágios (CARTWRIGHT, 1983, p. 133). O primeiro estágio é informal, começamos escrevendo tudo o que sabemos sobre o sistema/fenômeno em estudo, um grosseiro exagero que contém informações que consideramos relevantes e que nos ajudam a tomar o fio da meada; esta é a descrição despreparada, que está à esquerda do operador "como se" quando este é usado para expressar o compromisso existencial. Nesse ponto não existe distinção teoria-observação e escrevemos as informações que temos. Por exemplo, podemos saber que todos os elétrons do feixe têm spin para cima porque foram preparados desta forma; ou escrevemos as especificações técnicas para a construção dos espelhos do laser; ou que a cavidade é ocupada com átomos de hélio ionizado etc. e também se pode usar os conceitos e a linguagem da teoria, mas de fato a descrição despreparada não pode ser restringida pelos aspectos matemáticos da teoria. Neste primeiro estágio da teoria de entrada preparamos o fenômeno para trazê-lo para dentro da teoria, a fim de que a esta forneça uma equação matemática e os princípios que fazem a conexão entre o fenômeno e a teoria.

Porém, para resolvermos a equação, precisamos saber que condições-limite podem ser usadas, quais aproximações são válidas e então a descrição deve 
conter informações que especifiquem isso também. Por exemplo, podemos descrever as paredes e as vizinhanças da cavidade do laser como um reservatório com um grande número de modos ressonantes, o que significa que o laser não tem memória, ou seja, lança-se mão de uma aproximação que leva em conta apenas os fatos que atuam no sistema naquele momento, sem levar em conta sua história passada.

Não olhamos para um princípio ponte para que nos diga qual a forma adequada de tomar os fatos da descrição despreparada a fim de expressá-los de uma forma que reúna a matemática necessária da teoria. O controle da exatidão nesse estágio não está em como representar bem na teoria fatos que conhecemos fora da teoria, mas está apenas no sucesso final que o tratamento matemático terá.

Esse é um aspecto que contrasta em relação ao segundo estágio, onde os princípios da teoria olham para a descrição e ditam as equações, as condições-limite e as aproximações necessárias. Nesse segundo estágio, uma vez que decidimos tratar o $C W$ GaAs laser como um feixe fino com fonte no corpo negro, em vez de tratá-lo como "osciladores estabilizados", os princípios da MQ fornecerão equações que tratam disso. Então, embora tenhamos princípios ponte, estes não são universais e governam apenas o segundo estágio da teoria de entrada. No primeiro estágio não existem princípios teóricos, mas apenas regras manuseáveis e perspectivas de uma boa predição.

Cartwright concorda que essa descrição é bastante idealizada, mas propõe, ainda assim, que a levemos em conta porque teorias não são definitivas, estão sempre mudando, melhorando e expandindo e uma perspectiva nova pode oferecer um princípio ponte promissor.

\section{ALGUNS EXEMPLOS DE PRINCÍPIO “PONTE”}

A Mecânica Quântica (MQ) tomada como uma teoria fundamental exige, segundo Cartwright, uma reflexão sobre seus princípios. Se olharmos para a formalização típica da MQ, perceberemos que seus princípios fundamentais dividem-se em princípios internos e princípios ponte. Ela considera que o princípio interno fundamental é a equação de Schrödinger, que diz como sistemas sujeitos a várias forças evoluem no tempo. As forças, em geral, não aparecem de forma literal na equação, já que a MQ, baseada na formulação hamiltoniana da Mecânica Clássica, focaliza a energia. Em sua representação padrão, a equação de Schrödinger informa como um sistema quântico evolui no tempo quando o hamiltoniano é conhecido, sendo este uma representação matemática da energia cinética e potencial para o sistema. Princípios de conservação de energia, momento e paridade também podem aparecer como princípios internos.

A segunda classe de princípios fornece esquemas para entrar e sair da linguagem matemática da teoria: estados são representados por vetores; quantidades observáveis são representadas por operadores; valores médios de uma dada quantidade em um dado estado são representados por certo produto envolvendo 
o operador e o vetor apropriado. Mas, adverte Cartwright, saber tudo isso não implica saber MQ. Bons livros de texto de graduação tratam esses princípios em apenas um capítulo. A equação de Schrödinger diz como o sistema quântico evolui sob um dado hamiltoniano, mas para fazer Mecânica Quântica o sujeito tem que saber como selecioná-lo. Os princípios que nos falam como fazer isso são os princípios ponte da MQ. São eles que fornecem o conteúdo à teoria e é com eles que os estudantes gastam a maior parte do seu tempo de aprendizagem.

De maneira geral, se a visão convencional é adotada, os estudantes aprendem os princípios ponte trabalhando com formulação matemática de um lado e descrições de coisas reais de outro. Alguns livros de texto de nível mais avançado fazem várias discussões de situações concretas e dos hamiltonianos que as descrevem, e certas simplificações e idealizações com objetivos pedagógicos, mas menções a coisas concretas, feitas de materiais reais, estão praticamente ausentes.

Para Cartwright, a aprendizagem dos princípios da Mecânica Quântica segue uma sequência que ela denomina de "modelo hamiltoniano" cuja característica principal é focar objetos ficticios. Aprendemos hamiltonianos para o movimento de particula livre (em uma ou mais dimensões), para partícula em uma caixa, para oscilador harmônico linear, para a particula em um potencial constante (quadrado, degrau, periódico), para o átomo de hidrogênio, para moléculas diatômicas, para a teoria do laser etc. (CARTWRIGHT, 1983, p. 136) e, embora exista nessa lista um material real mencionado - o átomo de hidrogênio -, ele não pode ser tomado como um contraexemplo da postura assumida por Cartwright. $\mathrm{O}$ hamiltoniano que aprendemos para o átomo de hidrogênio não é o que se aplica a qualquer átomo de hidrogênio real. Átomos de hidrogênio reais aparecem em certos ambientes (um tanque muito frio ou uma molécula de benzeno) onde os efeitos do meio deveriam ser levados em conta na construção do hamiltoniano. O que se estuda, contudo, é um átomo de hidrogênio hipoteticamente isolado.

Mas essa não é única omissão importante. Albert Messiah, no livro Quantum Mechanics (Volume I), propõe um particular hamiltoniano e usa-o para obter a solução para o espectro de energia do hidrogênio e informa que "este espectro é justamente o predito pela Velha Mecânica Quântica; ele está em excelente acordo com o espectro experimental (...) mas não para sua estrutura fina” (MESSLAH, 1965.a, p. 419). A descoberta da estrutura fina do hidrogênio indicou outras omissões da teoria de Schrödinger, como, por exemplo, que esta não levava em conta a relatividade e o spin intrínseco do elétron. Em um segundo tratamento (MESSIAH, 1965.b, p. 875), a Teoria Relativística de Dirac é usada. Neste tratamento, os resultados experimentais da estrutura fina do átomo de hidrogênio e do íon de hidrogênio (He+) estão em boa concordância, mas não em perfeita concordância. Existem discrepâncias observadas na estrutura fina do nível $n=2$ do átomo de hidrogênio. A teoria prediz que estados com o mesmo $n$ e números quânticos $j$ diferentes, $l$ deve ser degenerado ${ }^{15}$. Mas, em um experimento de 1947, Lamb mostrou que os estados $2 \mathbf{s}_{1 / 2}(n=2, l=0, j=1 / 2)$ e $2 \mathbf{p}_{1 / 2}(n=2, l=1, j=1 / 2)$ do átomo de hidrogênio não eram degenerados. Esse resultado é conhecido como Efeito Lamb (o efeito 
Lamb é mais bem-explicado pela Eletrodinâmica Quântica) e exige um rigoroso tratamento da interação entre o elétron, o próton e o campo eletromagnético quantizado. Isso implica fazer "correções radioativas" já que a Teoria de Dirac conserva apenas o potencial de Coulomb que é o principal termo de interação.

Segundo Cartwright, nenhum desses tratamentos determina um hamiltoniano para o átomo de hidrogênio "real". O que fazemos é pensar como escrever o potencial de Coulomb entre o elétron e o próton, tanto no caso não relativístico como relativisticamente. Então, o que conhecemos como "o átomo de hidrogênio" é, na verdade, um sistema complexo e esse sistema de dois corpos que nós chamamos de "o átomo de hidrogênio” é meramente um construto mental (CARTWRIGHT, 1983, p.138).

O poder explicativo da Mecânica Quântica vem de sua habilidade de dispor de um pequeno número de hamiltonianos bem conhecidos e com eles dar conta de um grande número de casos. Se se requer um novo hamiltoniano para cada circunstância física, então a teoria é pobre. Mas o poder explicativo tem seu preço, argui ela, pois se limitamos o número de hamiltonianos estamos restringindo nossa habilidade de representar situações realisticamente. A realidade que conseguimos descrever é aquela que conseguimos "pintar", simplificar, representar através de modelos. Daí a importância e o papel destes: permitem o diálogo sobre o conhecimento que temos para explicar a realidade. Por isso, particularmente, Cartwright se debruça tanto nas questões fenomenológicas da Mecânica Quântica.

Possivelmente essa seja a maior contribuição da epistemologia de Cartwright para a sala de aula: o impacto da abordagem fenomenológica talvez não apareça tão fortemente nas explicações do mundo macroscópico, mais intuitivo, mas experimentos (virtuais, simulações computacionais), estudos ou metáforas através de um viés fenomenológico são ferramentas muito úteis para a compreensão de objetos e fenômenos microscópicos, dos conceitos fundamentais da MQ (por exemplo, dualidade onda-partícula, superposição de estados, etc.), dado que a transição do mundo macro para o micro não se resume a uma redução de escala, envolve uma nova Física, desafia a imaginação, requer apreender novos conceitos, novos fenômenos, novas entidades teóricas. Abordagens fenomenológicoconceituais para facilitar a compreensão dos alunos de conceitos da MQ não são novidades na Pesquisa em Ensino de Física (por exemplo, GRECA, MOREIRA e HERCOVITZ, 2001; SCHNEIDER e LA PUMA, 2002; HOLBROW et al., 2002). Esses autores informam resultados em que abordagens fenomenológicas são vantajosas para a compreensão de fenômenos microscópicos, em relação àquelas abstratas e muito atreladas ao formalismo matemático.

\section{CONSIDERAÇ̃̃ES FINAIS}

Como propõe Cartwright, precisamos distorcer a imagem do que ocorre na realidade se quisermos incluí-la nas estruturas altamente restritivas de nossas teorias matemáticas. É esse o sentido metafórico de que nossas descrições teóricas 
são inverdades. Ela ilustra esse aspecto da atividade científica através de uma metáfora: quando desejamos apresentar algum episódio histórico, primeiro estaremos interessados em mostrar as motivações e os comportamentos de participantes do episódio, mas se quisermos ser o mais possível realistas podemos dramatizar e, nesse caso, forçosamente teremos que fazer distorções dos fatos, da verdade histórica.

A ciência, uma conquista humana, está em busca de explicações cada vez melhores e força o cientista a aproximar a realidade, a representá-la através de modelos. Simplificações, aproximações e modificações estão associadas ao poder explicativo das teorias fundamentais e poupam o cientista do extenuante trabalho de ter que construir um emaranhado de leis, uma para cada circunstância.

Faz-se ciência, segundo Cartwright, construindo um repertório de entidades teóricas (modelos) a partir do nosso conhecimento do mundo, a partir dos princípios gerais das teorias fundamentais. Minha visão básica é que equações fundamentais não governam objetos da realidade; elas somente governam objetos em modelos (CARTWRIGHT, 1983, p. 129). Diferentes modelos têm diferentes objetivos. Depois se busca testar os modelos, comumente através de atividades colaborativas das comunidades científicas, no interior das quais se estabelecem padrões, estilos de pensamente e se tomam decisões. Os testes se dão através de leis fenomenológicas que são, ao fim, testes específicos de análogos dos modelos. Se o modelo é robusto, pode explicar com bom nível de precisão uma gama de fenômenos e eventos e prever comportamentos, propriedades e novos fenômenos, associando-os a prováveis causas. Quanto mais robusto o modelo, maior será sua efetividade e mais será preservado. Embora o cientista tenha consciência de que nunca um modelo descreve tudo o que acontece e que os requisitos teóricos limitam o que literalmente pode ser representado, as entidades teóricas, ou modelos, e as leis localizadas que os descrevem podem ser tomados realisticamente. Leis fundamentais não governam a realidade. O que elas governam tem apenas a aparência de realidade e a aparência é muito mais arrumada e mais facilmente arregimentada que a própria realidade (CARTWRIGHT, 1983, p. 162).

É nesse sentido que nossas melhores teorias fundamentais, aquelas que adquiriram grande poder explicativo, somente podem explicar através de entidades ideais (não descrevem regularidades da natureza) e exigem que se reinterprete seu realismo. Para isso, Cartwright nos convida a repensar a objetividade, a causalidade e o realismo, sob outra perspectiva, a partir das entidades teóricas ou modelos, se quisermos compreender a dinâmica da ciência dos nossos tempos. Suscitar reflexões e discussões de sala de aula a respeito dessas questões pode ser uma via capaz de transformar concepções sobre a natureza da ciência tanto de professores quanto de estudantes.

\section{NOTAS}

${ }^{1}$ Lei fundamental, na visão de Cartwright, é uma explicação ampla que abarca um grande número de fenômenos e possui uma estrutura composta por princípios e um conjunto de equações gerais como, por exemplo, as leis da mecânica de Newton sobre o movimento dos corpos ou as leis de Maxwell sobre os fenômenos eletromagnéticos. 
${ }^{2}$ Antirrealismo é tomado nesse contexto no sentido de que leis físicas fundamentais tratam de modelos ou entidades teóricas, que são construtos ou representações de objetos e fenômenos, não de objetos reais observáveis diretamente no mundo e constituídos de materiais reais. Em oposição, o realismo defende que as teorias científicas possuem valor de verdade porque seus enunciados teóricos referemse a entidades que realmente existem, revelam a estrutura causal do mundo (força, inércia, gravidade, por exemplo, não são invenções, mas entidades realmente existentes). Para um aprofundamento dessas ideias, sugerem-se leituras complementares (por exemplo, SILVA, 1998).

${ }^{3}$ Inferência é entendida como ato ou processo de derivar conclusões, por meio de raciocínio, a partir de premissas conhecidas ou tomadas como verdadeiras.

${ }^{4}$ Isotropia: propriedade fisicamente homogênea, isto é, tem o mesmo valor, ou intensidade, independente de direção e sentido. Alguns sólidos transparentes têm índice de refração igual em todas as direções de propagação da rede cristalina. Alguns exemplos são o vidro, o cloreto de sódio. Quando a propriedade varia com a direção e sentido, então o meio é anisotrópico.

${ }^{5}$ Ceteris paribus é uma expressão do latim que pode ser entendida como "todo o mais é constante" ou "mantidas inalteradas todas as outras coisas". Fonte: http://pt.wikipedia.org/wiki/Ceteris_paribus. Lakatos (1982, p.29) argumentou contra o falseacionismo dogmático ingênuo afirmando que teorias muito respeitadas como a dinâmica de Newton e a Gravitação podem não proibir nenhum fenômeno observável. Mas, arguiu ele, algumas teorias proíbem algum acontecimento, em alguma região espaçotemporal específica, desde que se admita que nenhum outro fator em nenhum lugar do universo tenha influência sobre ele. Isto é o mesmo que dizer que algumas teorias científicas incorporam uma cláusula ceteris-paribus. Contudo essa cláusula de não existência resulta de aceitação, por acordo, dos cientistas, e carece, portanto, de base empírica. http://pt.wikipedia.org/wiki/Ceteris_paribus.

${ }^{6}$ Richard Feynman: The Character of Physical Law (Cambridge, Mass: MIT Press, 1967).

7 Bas van Fraassen: The Scientific Image (Oxford: Clarendon Press, 1980).

${ }^{8}$ Hilary Putnam: Meaning and the Moral Sciences (London: Routledge and Kegan Paul, 1978).

${ }^{9}$ Pierre Duhem: The aim and structure of physics theory (NewYork: Atheneum, 1962).

${ }^{10}$ Ian Hacking é um filósofo da ciência atual, autor de uma obra intitulada Representing and Intervening (1983), traduzida para o português em 2012 pela Editora EDUERJ.

${ }^{11}$ Adição de vetores é, por exemplo, quando gravidade e eletricidade estão agindo simultaneamente, produzindo duas forças específicas: uma de acordo com a lei da Gravitação e outra de acordo com a lei de Coulomb, mas as duas se somam vetorialmente para produzir uma resultante.

${ }^{12}$ Modelo nomológico-dedutivo ( $N$-D model), segundo o qual as explicações científicas são argumentos dedutivamente válidos, ou seja, a partir de condições iniciais, de premissas e de leis universais ("nomológico" da palavra grega nómos, que quer dizer "lei"); a lógica dedutiva permite inferir explicações da coisa a ser explicada - fato ou fenômeno - e obtida dessa forma, a explicação científica pode predizer novos fenômenos. Esse modelo teve origem no chamado Círculo de Viena que teve como um dos propósitos conciliar a experiência com a lógica.

${ }^{13}$ Conhecimento causal é entendido como a busca do conhecimento através das causas; em vez de buscar justificações, investiga-se "o que", ou seja, a causa que o produziu. 
${ }^{14}$ Maser é um dispositivo que produz ondas eletromagnéticas coerentes através de amplificação por emissão estimulada. Historicamente, "maser" deriva de "MASER" sigla que significa "Microwave Amplification by Stimulated Emission of Radiation". $\mathrm{O}$ uso em minúsculas surgiu a partir do desenvolvimento tecnológico, que passou a usar a denotação original de forma imprecisa, uma vez que masers contemporâneos emitem ondas eletromagnéticas (micro-ondas e radiofrequências) em uma ampla faixa do espectro eletromagnético. Em 1957, quando o oscilador óptico coerente foi desenvolvido pela primeira vez, foi denominado maser óptico. Fonte: http://pt.wikipedia.org/wiki/Maser.

${ }^{15}$ Estados degenerados: em Mecânica Quântica uma degenerecência está associada ao fato de que vários estados quânticos distintos encontrarem-se ao mesmo nível de energia. $\mathrm{O}$ átomo de hidrogênio tem uma degenerescência de ordem $\mathrm{n}^{2}$, isto é, existem $\mathrm{n}^{2}$ estados diferentes do átomo de hidrogênio com energia $E_{n}$ e, se contarmos o spin, serão $2 n^{2}$.

\section{REFERÊNCIAS}

BACHELARD, G. Epistemología. Barcelona: Editorial Anagrama, 1973.

BUNGE, M. Teoria e realidade. São Paulo: Editora Perspectiva, 1974.

CARTWRIGHT, N. How the Laws of Physics Lie. New York: Oxford University Press, 1983.

CHALMERS, A.F. O que é ciência afinal? São Paulo: Editora Brasiliense, 1999.

GRECA, I. M.; MOREIRA, M.A. e HERSCOVITZ, V.E. Uma proposta para o ensino de Mecânica Quântica. Revista Brasileira de Ensino de Física, São Paulo, v.23, n.4, p. 444-457, 2001.

HOLBROW, C. H.; GALVEZ, E. e PARKS, M.E. Photon quantum mechanics and beam splitters. American Journal of Physics, v.70, n.3, p. 260-265, 2002.

LAKATOS, I. La metodología de los programas de investigación cientifica. Madrid: Alianza Universidad, 1982. MESSIAH, A. Quantum Mechanics, Volume I. Amsterdam: North-Holland, 1965.a.

MESSIAH, A. Quantum Mechanics, Volume II. Amsterdam: North-Holland, 1965.b.

POPPER, K. Conjecturas e refutacõoes. Brasília: Editora da Universidade de Brasília. 449 p., 1982.

SANTOS, M. R. Realismo e antirrealismo na ciência: aspectos introdutórios de uma discussão sobre a natureza das teorias. Revista Ciência \& Educação, 5(1), p. 7-13, 1998.

SCHNEIDER, M. B. e LA PUMA, I. A. A. A simple experiment for discussion of quantum interference and which-way measurement. American Journal of Physics, v.70, n.3, p. 266-271, 2002.

\section{Informaçōes:}

O presente trabalho trata de uma síntese interpretativa das ideias de Cartwright a partir da leitura crítica de sua obra original bem como por comparação a outras epistemologias, realizada pela primeira autora. O segundo autor revisou criticamente o trabalho, contribuiu com sugestões, correções de certos aspectos de escrita e fez acréscimos com respeito à Física abordada/mencionada pela epistemóloga estudada.

Data Recebimento: 20/11/2013

Data Aprovação: 05/11/2014

Data Versão Final: 28/11/2014

\section{Contato:}

Neusa Teresinha Massoni

Instituto de Física - Universidade Federal do Rio Grande do Sul

Caixa Postal 15051 - Campus - Porto Alegre, RS - Brasil

CEP: 91501-970. Email: moreira@if.ufrgs.br 
